\title{
Hacia un orden legal regional: Vicente Quesada y la construcción del derecho internacional latinoamericano*
}

\author{
Juan Pablo Scarfi*
}

Recibido el 20 de noviembre de 2018; aceptado el 3 de diciembre de 2018

\section{RESUMEN}

Aunque fue un diplomático de carrera y se vio implicado en el armado de los objetivos de la delegación argentina en la Primera Conferencia Panamericana (1889-1890), Vicente Quesada fue un precursor del antiimperialismo latinoamericano y de las teorías que postularon la existencia de un derecho internacional regional para América Latina. Antes de que el antiimperialismo latinoamericano comenzara a calar profundamente en el imaginario intelectual, diplomático y político latinoamericano, Quesada esbozó una serie de críticas contundentes a la Doctrina de Monroe como garante de la paz en América y al emergente panamericanismo promovido por James Blaine en el contexto de la Primera Conferencia Panamericana. Asimismo, precediendo a la institucionalización del derecho internacional como disciplina moderna en la Argentina y la construcción de una tradición legalista continental asociada al panamericanismo, Quesada publicó una serie de trabajos influyentes en los que intentó demostrar que la paz regional era producto de principios legales auténticamente latinoamericanos y no de la Doctrina de Monroe. Este artículo se funda en el estudio de estos trabajos de Quesada y argumen-

* Escuela de Política y Gobierno, Universidad Nacional de San Martín (UNSAM), correo electrónico: jpscarfi@gmail.com; jscarfi@unsam.edu.ar 
ta, entonces, que Quesada fue pionero en la postulación de una tradición latinoamericana del derecho internacional, abogando por la construcción de un orden legal regional latinoamericano resguardado del expansionismo estadounidense.

Palabras clave: Vicente Quesada, derecho internacional, América Latina.

\section{Towards a Legal Regional Order: Vicente Quesada and the Construction of Latin American International Law}

\section{AbSTract}

Although he was essentially a diplomat and was involved in the preparations for the plans for the Argentine delegation sent to the First Pan-American Conference (1889-1990), Vicente Quesada was a precursor of Latin American modern anti-imperialism and above all of the theories postulating the existence of a regional international law for Latin America. Before modern Latin American anti-imperialist ideas were incorporated within the intellectual, diplomatic and political Latin American imaginary, Quesada put forward a series of assertive critiques of the Monroe Doctrine as a safeguard to protect peace in the Americas and of the emerging Pan-American movement promoted by James Blaine in the context of the First Pan-American Conference. Moreover, preceding the institutionalization of international law as a modern discipline in Argentina and the construction of a continental legal tradition associated to Pan-Americanism, Quesada published a series of influential articles in which he sought to demonstrate that regional peace was the product of truly Latin American legal prínciples and not of the Monroe Doctrine. This article draws on these important pieces by Quesada and it argues that Quesada was pioneering in postulating a Latin American tradition of international law, advocating the construction of a regional Latin American legal order, safeguard from US expansionism.

Key words: Vicente Quesada, International Law, Latin America.

\section{INTRODUCCIÓN}

unque fue un diplomático de carrera y se vio implicado en el armado de Alos planes y objetivos de la delegación argentina en la Primera Conferencia Panamericana (1889-1890), Vicente Quesada fue un precursor del antiimperialismo latinoamericano y de las teorías que postularon la existencia de un derecho internacional regional para América Latina. Antes de que el antiimperialismo latinoamericano comenzara a calar profundamente en el imaginario intelectual, diplomático y político latinoamericano, Quesada 
esbozó una serie de críticas contundentes a la Doctrina de Monroe como garante de la paz en América y al emergente panamericanismo que comenzaba apenas a ser promovido por James Blaine a comienzos de la década de 1880 del siglo XIX, y que habría de dar lugar, hacia finales de esa década, a la Primera Conferencia Panamericana celebrada en Washington en 18891890. Asimismo, precediendo a la institucionalización del derecho internacional como disciplina moderna en la Argentina y en América Latina y a la construcción de una tradición legalista continental asociada al panamericanismo, Quesada publicó una serie de trabajos importantes y pioneros en los que intentó demostrar que la paz regional era producto de principios legales auténticamente latinoamericanos y no de la Doctrina de Monroe, la cual a su entender había sido proclamada de manera unilateral, egoísta y autointeresada por los Estados Unidos. Este artículo argumenta, entonces, que Quesada fue pionero en la postulación de una tradición latinoamericana del derecho internacional, abogando por la construcción de un orden legal regional latinoamericano autónomo y resguardado del expansionismo estadounidense.

Desde mediados del siglo XIX y de manera más contundente, hacia finales de ese siglo, surgió en América Latina, y de manera particularmente crítica en Argentina, un virulento discurso anti-estadounidense con ciertos componentes literarios modernistas, pero ante todo, con una impronta legalista y diplomática basada en una interpretación sofisticada y nostálgica de la historia diplomática latinoamericana y argentina. Lo irónico es que esa perspectiva nostálgica que volvía hacia el pasado colonial habría de tener un influjo y gravitación importante sobre generaciones futuras de intelectuales, diplomáticos, juristas y activistas latinoamericanos de comienzos y mediados del siglo $\mathrm{XX}$, en particular sobre figuras influyentes de la diplomacia mexicana de la Revolución, como Isidro Fabela y sobre Cuba en los tiempos de la Enmienda Platt. ${ }^{1}$ Este artículo examina tanto el contexto continental diplomático y geopolítico como el clima intelectual y diplomático que hicieron posible la emergencia de un imaginario moderno antiestadounidense y latinoamericanista del orden hemisférico en la diplomacia y la vida intelectual latinoamericana y argentina, una especie de identidad regional en la que el emergente discurso del derecho internacional fue un pilar central en la articulación de dicha identidad. Más específicamente, este artículo se propone analizar los fundamentos jurídicos e históricos de esta identidad y en particular de la idea de un derecho internacional latinoamericano, es decir,

\footnotetext{
Sobre Isidro Fabela y su concepción latinoamericanista del derecho internacional, véase Scarfi, "Globalizing the Latin American legal field: continental and regional approaches to the international legal order in Latin America”.
} 
su genealogía conceptual, concentrándome en la contribución y la trayectoria de Vicente Quesada. Quesada fue una figura pionera unas décadas antes de que comenzara a conformarse y consolidarse un derecho internacional americano y panamericanista continental que se formó en los albores del panamericanismo; también lo fue antes de redefinirse la Doctrina de Monroe como un principio hemisférico apropiado para la región en las primeras décadas del siglo XX de la mano del jurista chileno Alejandro Alvarez y del jurista estadounidense James Brown Scott para consolidarse dentro del marco del Instituto Americano de Derecho Internacional que unió a todas las sociedades nacionales de derecho internacional del continente. Así, Quesada fue a contramano de la historia del derecho internacional en el continente al proponer la construcción de un derecho internacional latinoamericano, fundado en principios contrapuestos a la Doctrina de Monroe y del panamericanismo que comenzaba a nacer. ${ }^{2}$

La literatura tradicional y la más reciente en la historia intelectual han tendido a referirse a este imaginario como estrictamente literario y casi exclusivamente dominado por un espíritu arielista, es decir, una interpretación cultural e idealista del imperialismo estadounidense. En su manifestación temprana y moderna se ha asociado con el llamado movimiento literario modernista, representado por José Martí, José Enrique Rodó y Rubén Darío. También se ha argumentado que este sesgo culturalista y literario ha limitado la comprensión de la naturaleza e implicancias del imperialismo estadounidense, lo cual llevó a los principales intelectuales de América Latina a elaborar análisis estrechos y superficiales de la política exterior de Estados Unidos y la naturaleza compleja de su dominación imperial y/o hegemónica en América Latina. Los trabajos pioneros de Oscar Terán y Nicola Miller han destacado de manera convincente estas limitaciones, sobre todo en el caso de la versión modernista del antiimperialismo latinoamericano. ${ }^{3}$

Más recientemente, una nueva historiografía más amplia sobre el antiimperialismo y el antiamericanismo comenzó a desarrollarse en América Latina y en el mundo anglo-americano. Por un lado, varios historiadores intelectuales y culturales de América Latina han comenzado a reexaminar las ideologías e imaginarios antiimperialistas y sus diversas repercusiones continentales prestando una especial atención a las redes intelectuales que se conformaron en torno de estas ideologías y movimientos de ideas, a las co-

2 Sobre el Instituto Americano de Derecho Internacional y sobre la Doctrina Monroe, véase Scarfi, The Hidden History of International Law in the Americas: Empire and Legal Networks.

3 Véase Terán, "El primer antiimperialismo latinoamericano", pp. 85-91 y Miller, In the Shadow of the State: Intellectuals and the Quest for National Identity in Twentieth-Century Spanish America, pp. 174-209. 
rrientes espiritualistas, teosóficas e indigenistas. Sin embargo, la mayor parte de estos estudios ha tendido a concentrarse predominantemente en la década de 1920, ya que fue para entonces que la ideología antiimperialista se popularizó y expandió masivamente en Argentina y en general en América Latina a partir del proceso de la Reforma Universitaria en la región, iniciado en $1918 .{ }^{4}$

Las ideas y proyectos jurídicos y diplomáticos de Vicente Gregorio Quesada florecieron al calor de la emergencia del naciente movimiento panamericanista y fueron expresión de algunas de las primeras reacciones latinoamericanistas y unionistas modernas. Quesada mantuvo lazos de solidaridad regional entablando amistad e intercambiando correspondencia con José Martí e invocando las nociones de "nuestra América" y de una Patria Grande en un intento de preservar la autonomía y la independencia de las naciones latinoamericanas. Estos lazos fueron fomentados por el hecho de que, además de ser un político, diplomático e intelectual de renombre con una formación formal universitaria en el campo del derecho, ocupando cargos en el Ministerio del Interior en Paraná en 1853, como diputado nacional por la Provincia de Corrientes en 1856 y como funcionario diplomático en la Cancillería en diversos años y como Ministro argentino en los Estados Unidos, Quesada fue un importante animador cultural e importante constructor de instituciones culturales en la Argentina al dirigir y crear la Revista del Paraná (1861), la Revista de Buenos Aires (1863-1871) y la Nueva Revista de Buenos Aires (1881-1885), además de oficiar como Director de la Biblioteca Nacional, entonces conocida como la Pública de la Provincia de Buenos

4 Véase Pita González, La Unión Latino Americana y el boletín Renovación: redes intelectuales y revistas culturales en la década de 1920; Devés Valdés y Melgar Bao, "Redes teosóficas y pensadores (políticos) latinoamericanos, 1910-1930”; Kersffeld, “La liga antiimperialista de las Américas: una construcción política entre el marxismo y el latinoamericanismo"; Bergel, "La desmesura revolucionaria. Prácticas intelectuales y cultura vitalista en los orígenes del APRA peruano (1921-1930)"; Ehrlich, "Una convivencia difícil: Manuel Ugarte entre el modernismo latinoamericano y el socialismo"; Melgar Bao, "La recepción del orientalismo antiimperialista en América Latina: 1924-1929”, Melgar Bao, "Un neobolivarianismo antiimperialista: La Unión Centro Sud Americana y de las Antillas [UCSAYA]", Melgar Bao, "Cominternismo intelectual: representaciones, redes y prácticas político-culturales en América Central, 1921-1933”; Bergel y Martínez Mazzola, “América Latina como práctica: Modos de sociabilidad intelectual de los reformistas universitarios (1918-1930)”. Los trabajos de Casaús Arzú y García Giráldez, Redes intelectuales centroamericanas. Un siglo de imaginarios nacionales (1820-1920); Bergel, “América Latina, pero desde abajo. Prácticas y representaciones intelectuales de un ciclo histórico latinoamericanista. 1898-1936”; Pita González y Marichal, Pensar el antiimperialismo: Ensayos de historia intelectual latinoamericana; Devés Valdés, Redes intelectuales en América Latina, son algunas de las pocas excepciones de trabajos que analizan períodos previos a 1920. 
Aires entre 1871 y $1879 .{ }^{5}$ Asimismo, sus ideas circularon a través de las revistas argentinas de la época que él mismo dirigió, como la Nueva Revista de Buenos Aires, dirigida por Vicente y su hijo Ernesto Quesada, y de otras como la revista La Biblioteca, dirigida por Paul Groussac, y la Revista de Derecho Historia y Letras, dirigida por Estanislao Zeballos. Aunque eran publicaciones dirigidas por las élites intelectuales y políticas argentinas, estas revistas se articularon alrededor de tres campos importantes del saber como el derecho, la historia y la literatura, tres preocupaciones que fueron centrales y practicadas con rigor por Vicente Quesada, y las mismas publicaron trabajos de autores y temáticas que trascendieron ampliamente las fronteras nacionales, como los congresos panamericanos, los ideales hispanistas en la región, la guerra Hispano-Norteamericana, la Revolución Mexicana y la Reforma Universitaria. Fueron, entonces, redes intelectuales con alcance continental pioneras en la promoción de un emergente imaginario antiestadounidense, reuniendo escritos y novedades políticas, jurídicas, diplomáticas y culturales de países diversos de la región, incluyendo a los Estados Unidos. Por ello, pueden ser vistas como precursoras de otras publicaciones que habrían de surgir unas décadas más tarde y que contribuirían a difundir dicho ideario antiimperialista de manera más amplia y con mayor impacto continental, como, por ejemplo, Renovación y Repertorio Americano. ${ }^{6}$ Hacia mediados de los años 1920, la ideología antiimperialista habría de ser también difundida por una serie de ligas y movimientos continentales que fueron emergiendo en diversos países latinoamericanos, como la Liga Antiimperialista de las Américas, creada en México; la Unión Latinoamericana, creada en Argentina; la Alianza Popular Revolucionaria Americana, concebida por el líder populista peruano Víctor Haya de la Torre; y la Unión Centro Sud Americana y de las Antillas, creada en México, entre otras. ${ }^{7}$

5 Buchbinder, Los Quesada: Letras, ciencias y política en la Argentina, 1850-1934, pp. 7997. En esta obra puede encontrarse un análisis detallado y minucioso de la biografía y trayectoria política, diplomática e intelectual de Vicente Quesada, así como también de su hijo Ernesto Quesada.

6 Sobre estas revistas, véase Pita González, "La discutida identidad latinoamericana: debates en el Repertorio Americano, 1938-1945” y Pita González, La Unión Latino Americana y el boletín Renovación: redes intelectuales y revistas culturales en la década de 1920.

7 Sobre estas organizaciones, ligas y redes antiimperialistas, ver Kersffeld, "La liga antiimperialista de las Américas: una construcción política entre el marxismo y el latinoamericanismo”; Pita González, La Unión Latino Americana y el boletín Renovación: redes intelectuales y revistas culturales en la década de 1920; Bergel, "La desmesura revolucionaria. Prácticas intelectuales y cultura vitalista en los orígenes del APRA peruano (19211930)"; Melgar Bao, "La recepción del orientalismo antiimperialista en América Latina: 1924-1929” y Melgar Bao, “Un neobolivarianismo antiimperialista: La Unión Centro Sud Americana y de las Antillas [UCSAYA]". 


\section{VICENTE QUESADA Y LA IDEA DE UN DERECHO INTERNACIONAL LATINOAMERICANO}

Quesada ofreció importantes argumentos jurídicos en favor del desarrollo de una tradición específicamente latinoamericana de derecho internacional, claramente distinguible de la tradición anglo-Americana, basada en el derecho común (common law). Por un lado, aunque el latinoamericanismo se originó hacia mediados del siglo XIX en Francia, fue en la Argentina que la idea de un derecho internacional latinoamericano fue originalmente concebida de la mano del propio Quesada. Éste se refirió específicamente a un derecho internacional latinoamericano en una serie de escritos de historia diplomática y derecho internacional, publicados en 1882 en la Nueva Revista de Buenos Aires, editada por él mismo y su hijo, Ernesto Quesada. ${ }^{8}$ Aunque estos escritos de Quesada son referenciados por algunos historiadores del derecho internacional de América Latina que se concentraron en la polémica suscitada entre los juristas argentinos Carlos Calvo y Amancio Alcorta en torno de los mismos, tal como destacamos más adelante y con mayor detalle, estos escritos y en particular el pensamiento jurídico de Quesada como articulador pionero de la idea de un derecho internacional latinoamericano han recibido en general muy poca atención y análisis de parte de historiadores y especialistas en derecho internacional. ${ }^{9}$

Quesada había sido influido por una tradición historiográfica y literaria romántica, nacionalista y nostálgica respecto del antiguo Virreinato del Río de la Plata, en particular por quien fuera "su amigo y maestro en historia" Vicente Fidel López (1815-1903), de quien fue además Secretario en el Ministerio de Relaciones Exteriores hacia 1852, así como también por el historiador José Manuel Estrada (1842- 1894). ${ }^{10}$ En su ensayo Derecho internacional latino-americano, Quesada desarrolló una defensa históricojurídica de lo que él mismo denominó el principio del "uti possidetis del año diez”, es decir, la reorganización del territorio hispanoamericano y la inte-

8 Véase Quesada, Historia diplomática latino-americana, Volumen 1: Derecho Internacional Latino-americano. La versión original salió publicada en la Nueva Revista de Buenos Aires en 1882.

9 Referencias a la polémica entre Calvo y Alcorta pueden encontrarse en Jacobini, Study of the Philosophy of International Law as Seen in the Works of Latin American Writers, p. 124; Esquirol, "Latin America”, p. 563, Becker Lorca, "International Law in Latin America or Latin American International Law? Rise, Fall and Retrieval of a Tradition of Legal Thinking and Political Imagination”, p. 302, y Scarfi, The Hidden History of International Law in the Americas: Empire and Legal Networks, pp. 64-65.

10 Sobre el romanticismo literario, histórico y político de López, véase el artículo de Jones en este dossier. Sobre la trayectoria intelectual y política de José Manuel Estrada, veáse a Bruno, Pioneros culturales de la Argentina. Biografías de una época, pp. 65-106. 
gridad territorial de las naciones que lo constituían inmediatamente después de la independencia sobre la base del estatus jurisdiccional y territorial monárquico previo al proceso independentista. ${ }^{11} \mathrm{~A}$ diferencia de su célebre y contemporáneo jurista, Carlos Calvo, quien consideraba que el derecho de gentes tenía un carácter universal, Quesada creía que las naciones hispanoamericanas disponían de reglas y normas que hacían de su propio derecho de gentes un corpus claramente distinguible del europeo. De hecho, inmediatamente después de su publicación en 1882, este escrito de Quesada provocó una polémica entre el célebre jurista argentino Carlos Calvo y Amancio Alcorta, en la cual el primero argumentó en contra de la existencia de un derecho de gentes específico para América Latina, mientras que el último se expresó a favor de dicha concepción. Tal polémica fue publicada también en las páginas de la Nueva Revista de Buenos Aires y tuvo un notable impacto en la discusión jurídica continental. ${ }^{12}$

Como fue el caso de una gran mayoría de los diplomáticos y juristas hispanoamericanos del siglo XIX y comienzos del siglo XX, Quesada fue un defensor del uti possidetis juris, es decir, de la idea según la cual las naciones tenían derecho y debían poseer los títulos jurisdiccionales establecidos y concedidos de acuerdo con los decretos del soberano y no las posesiones de facto. Quesada distinguió además este principio intrínsecamente hispanoamericano, esto es, el uti possidetis juris, de la Doctrina Monroe estadounidense proclamada en 1823 y sostuvo categóricamente que "la paz en América -Quesada se refería fundamentalmente a América Latina- reposa en el uti possidetis juris de 1810 ". ${ }^{13}$ Este principio se remitía al orden colonial instituido por el Rey de España Carlos III, quien había creado el Virreinato del Río de la Plata hacia 1776-1777 y se fundaba así en el supuesto de que los precedentes de organización y distribución territorial establecidos antes del proceso de independentista fijaban las posesiones territoriales de las naciones hispanoamericanas y servían de precedente para cualquier potencial disputa de fronteras posterior. Afirmaba así Quesada:

El principio del uti possidetis juris de 1810 es el que sirve para sostener la geografía política del continente, porque a la vez que es la regla de la demarcación entre los mismos estados, es el título de la soberanía territorial

11 Sobre el principio del uti possidetis de 1810 en el pensamiento y la tradición jurídica latinoamericana, véase el excelente artículo de Grandin, "The Liberal Traditions in the Americas: Rights, Sovereignty and the Origins of Liberal Multilateralism".

12 Véase Alcorta, "La ciencia del derecho internacional. Reseña de Carlos Calvo, Le droit international théorique et practique (Paris: 1880-1881)".

13 Véase Quesada, Historia diplomática latino-americana, Volumen 1: Derecho Internacional Latino-americano, p. 95. Véase también Cavaleri, La restauración del Virreinato: orígenes del nacionalismo territorial argentino, p. 48. 
de las naciones hispanoamericanas; es el origen de las soberanías internacionales y a la vez su garantía de conservación y de paz. ${ }^{14}$

En su carrera como diplomático en disputas territoriales y de frontera de la Argentina, así como también en este escrito consagrado a defender el principio del uti possidetis juris como fundamento de un derecho internacional auténticamente latinoamericano, Quesada demostró tener una nostalgia especial por el antiguo orden territorial del Virreinato del Río de la Plata, ya que ése era a su entender el punto de partida de la soberanía territorial que le pertenecía a Argentina y de la cual progresivamente había sido desposeída. El fundamento de la soberanía de Argentina residía fundamentalmente en el territorio, la bandera, la historia y la raza hispana y latina. La raza colonizadora era, junto con el territorio, el otro elemento fundante de la soberanía territorial, es decir, se trataba de dos principios entrelazados.

El derecho consuetudinario americano como base para la demarcación territorial de los nuevos estados tiene modificaciones peculiares según el origen de la raza colonizadora, o en otros términos, el principio jurídico que garantice la integridad territorial de los nuevos estados de origen español respectivamente, no es aplicable a las naciones que se han formado por la colonización inglesa o portuguesa. ${ }^{15}$

Para Quesada el fundamento de las demarcaciones territoriales de Argentina había sido definido por Carlos III creador del Virreinato del Río de la Plata. Por ello, el elemento racial establecido por el orden colonial ocupaba un lugar preponderante e incluso fundacional. Este elemento racial habría de ser fundamental para forjar este primer imaginario defensivo de una cultura hispana y latina que debía articularse en torno de una Unión Latinoamericana para resistir la expansión imperial de los Estados Unidos.

El escrito de Quesada fue publicado casi inmediatamente después de que el entonces Secretario de Estado, James G. Blaine, comenzara hacia 1881 a esbozar y difundir por el continente los planes y propósitos de lo que daría lugar más tarde a la Primera Conferencia Panamericana. De acuerdo con la invitación circulada en el contexto de esta temprana tentativa, el proyectado congreso americano se proponía "considerar y debatir los medios conducentes a prevenir las guerras entre las naciones de América". ${ }^{16}$ Esta primera tentativa no encontró suficiente apoyo por entonces, aunque sería retomada más tarde por el propio Blaine hacia finales de la misma década poniendo un

14 Quesada, Historia diplomática latino-americana, Volumen 1: Derecho Internacional Latinoamericano, p. 94.

15 Ibíd., p. 42.

16 Invitación y circular de Blaine, 29 de noviembre de 1881, citada en Quesada, Historia diplomática latino-americana, Volumen 1: Derecho Internacional Latino-americano, p. 81. 
énfasis adicional en la promoción del comercio y la inversión estadounidense en América Latina. Como muestra Healy, este segundo elemento resultó ser decisivo para encontrar mayor apoyo entre la opinión pública, los inversores, empresarios y el establishment político y diplomático estadounidense. ${ }^{17}$ La reacción de Quesada fue ostensiblemente escéptica respecto de esta primera tentativa panamericana que hiciera Blaine en 1881. Le parecía que el objetivo estadounidense de colaborar en la prevención de las guerras en América Latina promoviendo su actuación como tercer mediador entre las partes en conflicto era completamente estéril en la medida en que quienes actuaban como terceros no tenían ni podían tener poder coercitivo alguno para impedir la guerra. El escepticismo de Quesada estaba enraizado en una extraña especie de realismo geo-político de orientación legalista. Sostuvo así categóricamente: "Paréceme que con ese programa no tendrá éxito la futura y próxima conferencia diplomática”. ${ }^{18}$

\section{QUESADA Y LAS REACCIONES DEFENSIVAS FRENTE AL PANAMERICANISMO SURGIDO ENESTADOS UNIDOS}

Hacia finales de la década de 1880 y bajo los auspicios del secretario de Estado Blaine, la iniciativa de celebrar la Primera Conferencia Panamericana supo encontrar un mayor apoyo entre los inversores, comerciantes y la opinión pública estadounidenses. Quesada fue uno de los tres delegados argentinos, junto con Roque Sáenz Peña y Manuel Quintana, que fueron designados originalmente para representar a la Argentina en la Primera Conferencia Panamericana, celebrada en Washington en 1889-1890. Sin embargo, Quesada decidió deliberadamente no asistir a la reunión arguyendo que el papel que jugaría en la conferencia confrontando potencialmente con la delegación estadounidense hubiera tenido que moderarse para que no interfiriera con las funciones que cumplía como Ministro Argentino en Washington. En otras palabras, pensó que era más adecuado que los otros dos delegados argentinos que habían sido oficialmente designados se ocuparan de enfrentar y limitar las iniciativas estadounidenses. Por ello, Quesada se encontró con Sáenz Peña y Quintana en París y los tres se pusieron de acuerdo por unanimidad sobre todas las cuestiones que debían ser defendidas en la conferencia. Como cuenta su propio hijo Ernesto Quesada, por

17 Healy, James G. Blaine and Latin America.

18 Quesada, Historia diplomática latino-americana, Volumen 1: Derecho Internacional Latino-americano, p. 82. 
razones de prudencia Vicente Quesada procuró no estar presente en Washington en el contexto de la Conferencia. ${ }^{19}$

El panamericanismo en la temprana versión propugnada por Blaine constituyó una cristalización ideológica y diplomática del progresivo ascenso de los Estados Unidos como poder hegemónico en el continente americano. Fue ante todo una política hemisférica impulsada y liderada por los Estados Unidos de cooperación comercial, económica, legal, política e intelectual con América Latina, promoviendo instituciones continentales, valores y tradiciones comunes. ${ }^{20}$ En un contexto en el que la competencia económica y política imperial entre las potencias europeas por Asia y África estaba en ascenso, y Gran Bretaña y Alemania mantenían aún una hegemonía económica en América Latina, el panamericanismo se proyectó como una tentativa de desplazar la influencia europea y mayormente británica en la región, y establecer y consolidar una hegemonía comercial estadounidense. ${ }^{21}$

Las ideas e iniciativas para la conformación de un derecho internacional latinoamericano impulsados por Quesada, así como también sus reacciones defensivas frente al panamericanismo, fueron inspirados por iniciativas unionistas y de identidad continental que precedieron al panamericanismo y que sin duda se remontan a los inicios del período independentista de las naciones latinoamericanas y a las iniciativas de confederación propuestos por Simón Bolívar (1783-1830) y José Cecilio del Valle (1777-1834). Durante el siglo XIX, existieron intentos unionistas de diversa índole en pos de construir una federación latinoamericana de Estados. El más conocido fue el propuesto por Bolívar en el Congreso de Panamá en 1826. No obstante, como han mostrado Marta Elena Casaús Arzú y Teresa García Giráldez, las ideas pioneras confederativas para la conformación de una "Patria Grande" Americana fueron originalmente propuestas por Valle hacia 1822, cuatro años antes de que se celebrara a iniciativa de Bolívar el Congreso de Panamá (1826). Asimismo, las ideas liberales de Valle acerca de la Patria Grande para Centroamérica — difundidas a través de la publicación El Amigo de la Patria - estaban inspiradas en un concepto cívico amplio e inclusivo de la población y en principios territoriales que excedían la noción clásica de nación. ${ }^{22}$ De todos modos, en el imaginario continental de entonces el término que utilizaron Bolívar, Valle y también Francisco de Miranda para

19 Véase Quesada, Primera conferencia panamericana, pp. 4, 12.

20 Véase Healy, James G. Blaine and Latin America; Ardao, "Panamericanismo y latinoamericanismo” y Scarfi, El imperio de la ley.

21 Freeman Smith, "Latin America, the United States and the European Powers, 1830-1930", pp. 88-91.

${ }^{22}$ Véase Casaús Arzú y García Giráldez, Redes intelectuales centroamericanas. Un siglo de imaginarios nacionales (1820-1920), pp. 13-69. 
referirse a la identidad continental y a la necesidad de iniciar relaciones de solidaridad y cooperación entre los países del continente, pero ante todo consolidar y preservar la independencia recientemente conquistada, estuvo articulado alrededor de la noción de "americanismo". Un ejemplo más tardío de americanismo fue el que propuso en 1844 Juan Bautista Alberdi con una propuesta unionista y americanista similar a la de Bolívar, pero esbozando una identidad jurídica específica para la región al ser el primero en invocar la noción de "derecho internacional americano". ${ }^{23}$ Como ha observado Aimer Granados, hacia mediados del siglo XIX, tal como se comenzó a reflejar en sucesivos Congresos continentales, como el Congreso de Lima (1848), el de Santiago de Chile (1856) y el de Lima (1865), celebrados luego del Congreso de Panamá impulsado por Bolívar, el americanismo comenzó a ser reemplazado por el término hispanoamericanismo, ya que a partir de la formulación de la Doctrina Monroe, los estadounidenses comenzaron a apropiarse de la idea de América para hacer referencia exclusivamente a los Estados Unidos. ${ }^{24}$ El hispanoamericanismo surgió, entonces, de la necesidad de formular y afirmar una identidad continental común frente a los Estados Unidos. Paralelamente a la noción de Hispanoamérica surgió la noción de Latinoamérica, la cual se vio también informada por la expansión territorial que pusieron en marcha los Estados Unidos en México hacia mediados del siglo XIX. Como muestra Ardao, el unionismo latinoamericanista y defensivo que propuso durante la segunda mitad del siglo XIX el pensador Colombiano Torres Caicedo estuvo ostensiblemente influido por el proceso imperial expansivo impulsado por la potencia del norte. ${ }^{25}$ De hecho, Torres Caicedo fue un pensador pionero al invocar por primera vez de manera explícita la idea de una "Unión Latinoamericana” y fue además una referencia intelectual para Quesada. ${ }^{26}$

La versión unionista impulsada por Quesada se conformó en los albores del surgimiento del panamericanismo y por ello sus ideas y proyectos para la conformación de un derecho internacional latinoamericano constituyeron una nueva reacción defensiva moderna de orientación legalista y diplomática. Sus ideas estuvieron marcadas por una nostalgia respecto de una Patria Grande que fue progresivamente desposeída de sus territorios y poblaciones a partir de la disolución del Virreinato del Río de la Plata que se inició a

23 Véase Alberdi, "Memoria sobre la conveniencia y objetos de un Congreso Americano (1844)", pp. 45-60.

24 Véase Granados, "Congresos e intelectuales en los inicios de un proyecto y de una conciencia continental latinoamericana, 1826-1860".

25 Véase Ardao, "Panamericanismo y latinoamericanismo".

26 Véase Torres Caicedo, Unión Latino-Americana; McGann, Argentina, the United States, and the Inter-American system, 1880-1914, pp. 67-68, 96-97. 
partir de la independencia de Argentina. De este modo, Quesada estuvo a mitad de camino entre el unionismo latinoamericanista y defensivo de las élites intelectuales latinoamericanas del siglo XIX, como fue el caso de Torres Caicedo y el antiimperialismo de carácter más popular y estudiantil “desde abajo" que surgió en la década de 1920 de la mano de ideas teosóficas, indigenistas, y diversas variantes del socialismo y el comunismo, a través de diversas redes intelectuales y de solidaridad de mayor alcance. ${ }^{27}$

Aunque no se publicaría hasta 1893 y aparecería bajo el seudónimo de Domingo de Pantoja, el polémico escrito titulado Los Estados Unidos y la América del Sur: Los yankees pintados por sí mismos había sido concebido en el contexto de los preparativos y planes de la Primera Conferencia Panamericana mientras Quesada ocupaba el cargo de Ministro Argentino en Washington. ${ }^{28}$ Por ello es un escrito híbrido y de transición, ya que si bien sigue en gran medida la tradición del género de los escritos de viajeros argentinos a los Estados Unidos, se trata de la visión de alguien que frecuentó la sociedad estadounidense desde dentro en calidad de diplomático, como sería el caso más tarde de Martín García Mérou, quien ocuparía el mismo cargo de Quesada, pero desarrollaría una visión radicalmente opuesta. ${ }^{29}$ Como ha destacado Pagés Larraya, no fue sino el propio José Martí, quien animó a Vicente G. Quesada a publicar sus impresiones críticas acerca de los Estados Unidos, tal como habían sido esbozadas en ese polémico escrito. ${ }^{30}$

\section{CONCLUSIÓN}

En este artículo me propuse analizar el contexto continental y regional en el que se configuró el pensamiento jurídico de Quesada y la gran importancia que se le asignó al lenguaje jurídico en la construcción de un proyecto para un orden regional legal latinoamericano antiestadounidense desde la Argentina. En primer lugar, cabe destacar que el contexto argentino fue particularmente propicio no sólo para la germinación y el desarrollo de este lenguaje que fue a contramano de las tendencias del pensamiento internacio-

27 Véase Bergel, “América Latina, pero desde abajo. Prácticas y representaciones intelectuales de un ciclo histórico latinoamericanista. 1898-1936".

28 Véase McGann, Argentina, the United States, and the Inter-American system, 1880-1914, p. 158; Quesada (Domingo de Pantoja), Los Estados Unidos y la América del sur: Los yankees pintados por sí mismos.

29 Sobre los imaginarios de los Estados Unidos en los libros de viajes de intelectuales argentinos de este período y sobre la visión de García Mérou de los Estados Unidos, ver Bruno (2013), "Estados Unidos como caleidoscopio. Ensayo sobre las observaciones de viajeros y diplomáticos argentinos del fin de siglo,” pp. 23-38.

30 Véase Pagés Larraya, “Bosquejo sobre Vicente G. Quesada”, p. 77. 
nal continental panamericanista y liberal internacionalista de esos años, sino también para la gestación de importantes interacciones y puntos de confluencia entre escritores modernistas como Martí, Rodó y Groussac, por un lado, y juristas de la élite patricia gobernante que tenían una impronta antiestadounidense y latinoamericanista como Quesada, por otro.

Aunque suele afirmarse que el primer antiimperialismo latinoamericano nació en los albores de las intervenciones estadounidenses en Centroamérica y en el Caribe en el contexto de la guerra hispano-norteamericana de 1898 como parte de una reacción cultural protagonizada por los escritores modernistas, este artículo se propuso mostrar, en segundo lugar, que durante la década de 1880 Quesada comenzó a forjar la noción de un derecho internacional latinoamericano en una serie de estudios de historia diplomática y derecho internacional, así como también en iniciativas diplomáticas concretas un poco antes y mientras comenzaba a conformarse en los Estados Unidos el movimiento panamericanista de la mano de James Blaine a comienzos de los 1880. Existieron, entonces, dos puntos de inflexión en la formación de un proyecto para un orden regional latinoamericano. Como he intentado mostrar, en un primer momento, durante la década de 1880, existió una reacción legalista defensiva frente al emergente panamericanismo y recién una década más tarde, en 1898, comenzó a desarrollarse un registro culturalista y moralista condenatorio de las intervenciones estadounidenses y la Doctrina Monroe que tendió a confluir con el discurso legalista que había nacido una década antes y que se mantuvo muy vivo hasta 1913 en figuras como Quesada.

Por último, la propuesta de Quesada fue pionera y precursora de un antiimperialismo con matices legalistas que enfatizó la importancia de preservar la paz y resolver los conflictos regionales de manera legal y pacífica a través de un entendimiento geopolítico del espacio regional, basado en una idea de un derecho internacional específicamente latinoamericano e hispanoamericano, diferenciado por un lado de las colonias portuguesas de Brasil, así como también de las colonias inglesas, establecidas en los Estados Unidos. Este antiimperialismo legalista y regional tendría una gravitación durante las primeras décadas del siglo XX entre otros juristas y diplomáticos argentinos, mexicanos y cubanos, a diferencia del pacifismo surgido de la mano del intento de regionalizar o continentalizar la Doctrina Monroe para proteger a la región de las intervenciones europeas o del naciente panamericanismo. Este último era promovido por el Secretario de Estado estadounidense, James Blaine, quien propugnaba el arbitraje y la resolución pacífica y legal de los conflictos continentales. Este pacificismo rechazó la Doctrina de Monroe como medio para preservar la paz y destacó la existencia de mecanismos legales e históricos regionales para resolver disputas y preservar la 
integridad territorial de la Argentina y de los países de hispánicos de América Latina, como el uti possidetis juris que podían contribuir a consolidar y fortalecer un orden legal regional resguardado de los conflictos bélicos internos, pero también del ascenso y la emergente hegemonía de los Estados Unidos en la región de América Latina.

\section{BiBLIOGRAFÍA}

Alberdi, Juan Bautista, "Memoria sobre la conveniencia y objetos de un Congreso Americano (1844)”, Díaz Cisneros, César, Alberdi ante la filosofía y el derecho de gentes. La Plata, Talleres Gráficos Olivieri y Domínguez, 1930, pp. 45-60.

Alcorta, Amancio, "La ciencia del derecho internacional. Reseña de Carlos Calvo, Le droit international théorique et practique (Paris: 1880-1881)”, Nueva Revista de Buenos Aires, Buenos Aires, vol. 7,1883, pp. 406-437.

Ardao, Arturo, "Panamericanismo y latinoamericanismo", Zea, Leopoldo (ed.), América Latina en sus ideas, Méxic, Siglo XXI editores, 1986, pp. 157-171.

Becker Lorca, Arnulf, “International Law in Latin America or Latin American International Law? Rise, Fall and Retrieval of a Tradition of Legal Thinking and Political Imagination,” Harvard International Law Journal, vol. 47, no. 1, 2006, pp. 283-305.

Bergel, Martín, "La desmesura revolucionaria. Prácticas intelectuales y cultura vitalista en los orígenes del APRA peruano (1921-1930)”, Altamirano, Carlos (ed.), Historia de los intelectuales en América Latina, tomo II. Buenos Aires, Katz, 2010, pp. 301-324.

, “América Latina, pero desde abajo. Prácticas y representaciones intelectuales de un ciclo histórico latinoamericanista. 1898-1936”, Cuadernos de Historia. Santiago de Chile, núm. 36, 2012, pp. 7-36.

Bergel, Martín y Martínez Mazzola, Ricardo, “América Latina como práctica: Modos de sociabilidad intelectual de los reformistas universitarios (1918-1930)”, Altamirano, Carlos (ed.), Historia de los intelectuales en América Latina, tomo II, Buenos Aires, Katz, 2010, pp. 119-145.

Bruno, Paula, "Estados Unidos como caleidoscopio. Ensayo sobre las observaciones de viajeros y diplomáticos argentinos del fin de siglo,” Revista Complutense de Historia de América, ním. 39, 2013, pp. 23-38.

Bruno, _- Pioneros culturales de la Argentina. Biografías de una época, Buenos Aires, Siglo XXI editores, 2011.

Buchbinder, Pablo, Los Quesada: Letras, ciencias y política en la Argentina, 18501934, Buenos Aires, Edhasa, 2012.

Casaús Arzú, Marta Elena y García Giráldez, María Teresa, Redes intelectuales centroamericanas. Un siglo de imaginarios nacionales (1820-1920), Guatemala, F y G Editores, 2005. 
Cavaleri, Paulo, La restauración del Virreinato: orígenes del nacionalismo territorial argentine, Buenos Aires, Universidad Nacional de Quilmes, 2004.

Devés Valdés, Eduardo, Redes intelectuales en América Latina, Santiago de Chile, Instituto de Estudios Avanzados-Universidad de Chile, 2007.

Devés Valdés, Eduardo y Melgar Bao, Ricardo, "Redes teosóficas y pensadores (políticos) latinoamericanos, 1910-1930”, Devés Valdés, Redes interculturales en América Latina, Santiago de Chile, Instituto de Estudios AvanzadosUniversidad de Chile, 2007.

Ehrlich, Laura, "Una convivencia difícil: Manuel Ugarte entre el modernismo latinoamericano y el socialismo”, Políticas de la memoria. Buenos Aires, núms. 6-7, 2007, pp. 105-119.

Esquirol, Jorge L., "Latin America”, Bardo Fassbender y Anne Peters (eds.), The Oxford Handbook of the History of International Law, Oxford, Oxford University Press, pp. 553-577.

Friedman, Max Paul, Rethinking anti-Americanism: the history of an exceptional concept in American foreign relations, Cambridge, Cambridge University Press, 2012.

Freeman Smith, Robert, "Latin America, the United States and the European Powers, 1830-1930”, Leslie Bethell (ed.), The Cambridge History of Latin America, vol. 4, Cambridge. Cambridge University Press, 1986, pp. 83-120.

Granados, Aimer, "Congresos e intelectuales en los inicios de un proyecto y de una conciencia continental latinoamericana, 1826-1860”, Aimer Granados y Carlos Marichal, eds., Construcción de las identidades latinoamericanas: ensayos de historia intelectual, siglos XIX y XX, México, El Colegio de México, 2004, pp. 39-69.

Granados, Aimer y Marichal, Carlos (eds.), Construcción de las identidades latinoamericanas: ensayos de historia intelectual, siglos XIX y XX, México, El Colegio de México, 2004.

Grandin, Greg, "Your Americanism and Mine: Americanism and Anti-Americanism in the Americas", American Historical Review, vol. 111, 2006, pp. 10421066.

, "The Liberal Traditions in the Americas: Rights, Sovereignty and the Origins of Liberal Multilateralism”. American Historical Review, vol. 117, 2012, pp. 68-91.

Halperín Donghi, Tulio, “La imagen argentina de Bolívar, de Funes a Mitres”, en El espejo de la historia. Buenos Aires, Editorial Sudamericana, 1987, pp. 111139.

Healy, David, James G. Blaine and Latin America, Columbia, MO, University of Missouri Press, 2001.

Jacobini, H. B., Study of the Philosophy of International Law as Seen in the Works of Latin American Writers, The Hague, Martinus Nijhoff, 1954. 
Kersffeld, Daniel, "La liga antiimperialista de las Américas: una construcción política entre el marxismo y el latinoamericanismo”, Políticas de la memoria. Buenos Aires, núms. 6-7, 2007, pp. 143-148.

Lawrence, William Beach, Commentaire sur les eléments de droit international et sur l'histoire des progrès de droit des gens de Henry Wheaton, Leipzig, Brockhaus, vol II, 1869.

Martí, José, Argentina y la Primera Conferencia Panamericana, Buenos Aires, Ediciones Transición, 1955.

_ Obras completas: volumen 20. Epistolario, La Habana, Editorial Nacional de Cuba, 1965. , Epistolario: antología, Madrid, Editorial Gredos, 1973.

McGann, Thomas F., Argentina, the United States, and the Inter-American system, 1880-1914. Cambridge, MA. Harvard University Press, 1957.

McPherson, Alan L. (ed.), Anti-Americanism in Latin America and the Caribbean. NewYork. Berghahn Books, 2006.

Melgar Bao, Ricardo, "La recepción del orientalismo antiimperialista en América Latina: 1924-1929”, Cuadernos Americanos, Nueva Época, México, vol. 1, núm. 109, 2005, pp. 11-41.

, "Un neobolivarianismo antiimperialista: La Unión Centro Sud Americana y de las Antillas [UCSAYA]”, Políticas de la memoria, Buenos Aires, núms. 6-7, 2007, pp. 149-163.

_ _ "Cominternismo intelectual: representaciones, redes y prácticas políticoculturales en América Central, 1921-1933”, Revista Complutense de Historia de América, Madrid, núm. 35, 2009, pp. 135-159.

Miller, Nicola, In the Shadow of the State: Intellectuals and the quest for national identity in twentieth-century Spanish America, London, Verso, 1999.

Moyano, Javier, "El concepto de América Latina en el pensamiento de Manuel Ugarte y Deodoro Roca”, Granados, Aimer y Marichal, Carlos (eds.), Construcción de las identidades latinoamericanas: ensayos de historia intelectual, siglos XIX Y XX, México, El Colegio de México, 2004, pp. 179-205.

Pagés Larraya, Antonio, “Bosquejo sobre Vicente G. Quesada”, Quesada, Vicente, Memorias de un viejo: Escenas de costumbres de la República Argentina, Buenos Aires, Academia de Letras, 1990, pp. 11- 93.

Pérez, Jr, Louis A., The war of 1898: the United States and Cuba in history and historiography. Chapel Hill, University of North Carolina Press, 1998.

Pita González, Alexandra, "La discutida identidad latinoamericana: debates en el Repertorio Americano, 1938-1945”, Granados, Aimer y Marichal, Carlos (eds.), Construcción de las identidades latinoamericanas: ensayos de historia intelectual, siglos XIX y XX, México, El Colegio de México, 2004, pp. 241265.

, La Unión Latino Americana y el boletín Renovación: redes intelectuales y revistas culturales en la década de 1920. México. Colegio de México, 2009. 
Pita González, Alexandra y Marichal, Carlos (eds.), Pensar el antiimperialismo: Ensayos de historia intelectual latinoamericana, México, El Colegio de México, 2012.

Quesada, Ernesto, Primera conferencia panamericana, Buenos Aires, Imprenta Scheone, 1919.

Quesada, Vicente Gregorio, Los Estados Unidos y la América del sur: Los yankees pintados por sí mismos, Buenos Aires, Imprenta J. Peuser (Seudónimo Domingo de Pantoja), 1893.

— Historia diplomática latino-americana, Volumen 1: Derecho Internacional Latino-americano, Buenos Aires, La Cultura Argentina, [1882] 1918.

Ramos, Julio, "Hemispheric Domains: 1898 and the Origins of Latin Americanism”, Journal of Latin American Cultural Studies. Londres, vol. 10, no 3, 2001, pp. 237-251.

Scarfi, Juan Pablo, “Globalizing the Latin American legal field: continental and regional approaches to the international legal order in Latin America," Revista Brasileira de Política Internacional 61, no. 2, 2018, pp. 1-12.

- The Hidden History of International Law in the Americas: Empire and Legal Networks, New York, Oxford University Press, 2017.

— El imperio de la ley: James Brown Scott y la construcción de un orden jurídico interamericano, Buenos Aires, Fondo de Cultura Económica, 2014.

Terán, Oscar, “El primer antiimperialismo latinoamericano”, Oscar Terán, En busca de la ideología argentina, Buenos Aires, Catálogos, 1986, pp. 85-97.

Torres Caicedo, Jose María, Unión Latino-Americana, París, Rosa y Bouret, 1865. 